\title{
PENGEMBANGAN ADSORBENT BED UNTUK PENINGKATAN KONDUKTIVITAS TERMAL MELALUI PENAMBAHAN PARTIKEL METAL ALUMINIUM
}

\author{
Didik Ariwibowo, Sutrisno \\ Program Studi Diploma III Teknik Mesin \\ Fakultas Teknik Universitas Diponegoro
}

\begin{abstract}
Didik Ariwibowo, Sutrisno, in this paper explain that this research is to increase thermal conductivity of a adsorbent bed by adding metal particles in it so that the bed become a granule-mixed bed. The adsorbent bed contains activated-carbon granule and aluminium particles. The research activity include: design and fabrication of adsorbent bed prototype following thermal performance study of the adsorbent bed. The thermal performance study of the adsorbent bed was conducted by varying metal/adsorbent ratio of 5\%, 10\%, 15\% by volume. The result showed that adding 5\%, 10\%, and 15\% aluminium particles into adsorbent bed has increased its thermal conductivity, those are $10,9 \mathrm{Wm}^{-1} \mathrm{~K}^{-1} ; 21,9 \mathrm{Wm}^{-1} \mathrm{~K}^{-1}$; and $30,9 \mathrm{Wm}^{-1} \mathrm{~K}^{-1}$ respectively from $1,6 \mathrm{Wm}^{-1} \mathrm{~K}^{-1}$ activated carbon thermal conductivity. The values of experimental thermal conductivity were higher than those of calculated thermal conductivity. The percentage of the difference between experimental thermal conductivity and calculated thermal conductivity decreased as bed surface temperature increased. The relatively higher percentage was in $45 \%$ whereas the lower was $10 \%$. The lower range of the difference was 10-20\% occurred in $55-65^{\circ} \mathrm{C}$ temperature range.
\end{abstract}

Key words: adsorbent bed, metal/adsorbent ratio, thermal conductivity

\section{PENDAHULUAN}

Salah satu media yang digunakan pada sistem pendingin adsorbsi adalah karbonaktif/methanol karena dapat dikendalikan oleh panas yang relative rendah dengan temperatur mendekati temperatur atmosfer (Lemmini, 1990; Pons, 1987; Pons, 1986). Selain sifat-sifat yang terkait dengan termal, material adsorben harus mempunyai porositas yang tinggi. Material adsorben yang umum digunakan adalah silica gel, karbon aktif, alumina, dan zeolit. Sedangkan pasangan material yang sering digunakan pada sistem pendingin adalah zeolit/air dan karbonaktif/methanol. Kedua pasangan tersebut mempunyai sifat fisik yang sangat berbeda. Metanol mudah dilepaskan dari karbon aktif ketika dipanaskan, sedangkan dalam zeolit, air tertahan cukup lama (Wang, 2006). Pasangan karbonaktif/methanol cukup baik dalam beradaptasi pada operasi siklus dengan variasi temperatur evaporasi yang kecil, sedangkan pasangan zeolit/air membutuhkan perubahan temperatur evaporasi yang lebih besar untuk beroparasi (Meunier, 1990).

Untuk meningkatkan pemanasan adsorben, kolektor surya model plat dengan permukaan selektif dan bentik kolektor parabolic telah digunakan. Kehilangan panas dari kolektor ke lingkungan ditingkatkan dengan peralatan isolasi yang dapat dipindah, flap atau damper (Critoph, 1994). Beberapa disain mengkombinasikan kolektor dan kondensor bentuk fin pada satu unit (Meunier, 1994).

Pada penelitian lain, pendekatan yang berbeda dikembangkan untuk memperbaiki laju perpindahan panas dan meningkatkan pemanasan dan pendinginan dari adsorben. Penggunaan adsorben komposit dan karbon monolitik merupakan metode yang dikembangkan tersebut untuk meningkatkan konduktivitas termal dan densitas adsorben (Khattab, 2004).

Kebanyakan sistem refrigerasi adsorbsi menggunakan desain adsorbent bed berbentuk butiran adsorben. Jenis adsorbent bed seperti ini memiliki keuntungan dalam performa perpindahan massa yang tinggi dikarenakan tingkat permeabilitasnya tinggi (Freni, 2009). Namun, tipe ini memiliki performa perpindahan kalor yang kurang baik karena adanya hambatan termal kontak antara adsorben dan permukaan dinding metal penukar kalor (Restuccia, 2002), diskontinyuitas perpindahan kalor melalui butiran adsorben karena celah antar butiran (Eun, 2000), dan konduktivitas adsorben rendah yang merupakan sifat fisik dari adsorben tersebut. Oleh karenanya, banyak metode dikembangkan untuk menginvestigasi peningkatan performa perpindahan kalor dari adsorben seperti pelapisan butiran adsorben dengan bahan metal (Restuccia, 2002), perekatan adsorben dengan bahan perekat metal (Wang, 2005), dan pencetakan adsorben dengan metal foam (Hu, 2009). Metodemetode tersebut dapat meningkatkan performa perpindahan kalor dari bahan adsorben tetapi akan menurunkan performa perpindahan massa. Untuk itu, pengembangan tipe adsorben bed perlu dilakukan.

Penelitian ini dimaksudkan untuk meningkatkan konduktivitas termal adsorben dengan cara memberikan penambahan butiran metal ke dalam adsorbent bed sehingga menjadi suatu campuran butiran dalam suatu bed. 


\section{METODE PENELITIAN}

\section{Desain dan Pabrikasi Adsorbent Bed}

Desain dan pabrikasi adsorbent bed dikerjakan di Workshop Teknik Mesin PSD III UNDIP. Desain prototipe adsorbent bed ini tersaji pada Gambar 1. Adsorbent bed ini dikonstruksi dengan bagian utama: (1) Rangka resin, (2) cover kaca, dan (6) ruang untuk partikel aluminium/karbon aktif.

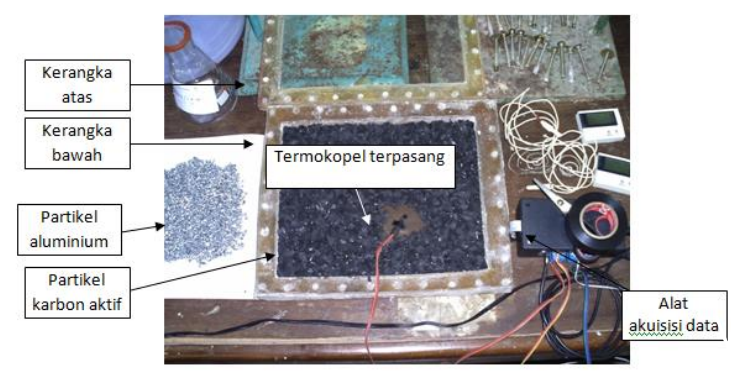

Gambar 1. Adsorbent bed

\section{Bahan Penelitian}

Bahan yang dipakai dalam penelitian ini adalah partikel karbon aktif dan methanol, yang dibeli dari toko bahan kimia, dan partikel aluminium yang diperoleh dari toko bahan teknik.

\section{Alat Penelitian}

Peralatan utama pada penelitian ini adalah berupa adsorbent bed yang terangkai dengan alat akuisisi data seperti tersaji pada Gambar 2. Sedangkan alat yang digunakan sebagai pendukung adalah penakar volume, lampu, dan thermometer ruang.

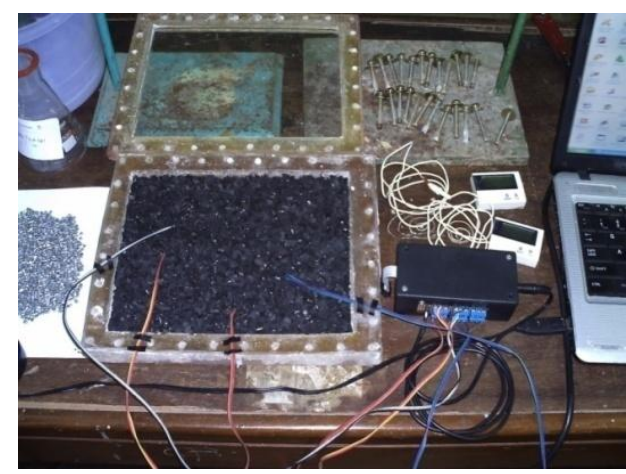

Gambar 2. Rangkaian adsorbent bed dengan akuisisi data

Telaah pengaruh rasio partikel metal/adsorben terhadap konduktivitas termal adsorbent bed

Telaah rasio partikel metal/adsorben, sebagai variable eksperimen, bertujuan untuk meningkatkan konduktivitas termal dari adsorbent bed. Kajian dilakukan dengan mengatur rasio partikel metal/adsorben. Rasio partikel metal/adsorben diatur pada rentang 5\%, 10\%, dan $15 \%$.

\section{PROSEDUR PERCOBAAN}

Persiapan bahan

Karbon aktif dan partikel aluminium disaring secara terpisah untuk mendapatkan ukuran partikel rata-rata 3-5 mm untuk karbon aktif dan 2$3 \mathrm{~mm}$ untuk partikel aluminium, kemudian kedua bahan ditakar dengan rasio 5, 10, 15\% volume dan dicampurkan. Campuran kedua partikel direndam di dalam methanol kemudian dimasukkan ke dalam adsorbent bed. Agar campuran partikel aluminium/karbon aktif terjadi secara random, maka proses pencampuran dilakukan secara acak dan setiap rasio dilakukan perulangan pencampuran 5 kali.

\section{Proses Pemanasan dan Desorbsi pada Adsorbent} Bed

Setelah adsorben bed terangkai, proses pemanasan dilakukan dengan tahapan sebagai berikut:

- Adsorbent bed dipanasi menggunakan lampu pemanas.

- Temperatur termonitor dalam akuisisi data setiap 20 detik.

\section{Interpretasi Data}

Temperatur bagian atas dan bagian bawah adsorbent bed, yang termonitor oleh akuisisi data, digunakan sebagai data untuk kalkulasi penentuan konduktivitas termal adsorbent bed. Metode berbasis volume digunakan untuk memprediksi konduktivitas termal campuran aluminium/adsorben, dengan persamaan (Demir, 2010):

$\mathrm{K}=\left[\mathrm{k}_{1} \mathrm{~V}_{1}(\mathrm{dT} / \mathrm{dx})_{1}+\mathrm{k}_{2} \mathrm{~V}_{2}(\mathrm{dT} / \mathrm{dx})_{2}\right] /\left[\mathrm{V}_{1}(\mathrm{dT} / \mathrm{dx})_{1}+\right.$ $\left.\mathrm{V}_{2}(\mathrm{dT} / \mathrm{dx})_{2}\right]$

$\mathrm{k}_{1}$ dan $\mathrm{V}_{1}$ adalah konduktivitas termal dan fraksi volume metal sedangkan $\mathrm{k}_{2}$ dan $\mathrm{V}_{2}$ adalah konduktivitas termal dan fraksi volume adsorben. Gradien temperatur $(\mathrm{dT} / \mathrm{dx})_{1}$ dan $\quad(\mathrm{dT} / \mathrm{dx})_{2}$ campuran ditentukan dengan persamaan:

$$
(\mathrm{dT} / \mathrm{dx})_{1} /(\mathrm{dT} / \mathrm{dx})_{2}=\mathrm{nk}_{1} /\left[\mathrm{k}_{2}+(\mathrm{n}-1) \mathrm{k}_{1}\right]
$$

Faktor (n) tergantung pada bentuk metal aditif (Hamilton, 1962)

\section{HASIL DAN DISKUSI}

\section{Kenaikan temperatur fungsi waktu}

Gambar 3 memperlihatkan profil kenaikan temperatur fungsi waktu. Sumbu horizontal adalah waktu pencacahan, yang terjadi setiap 20 detik, sedangkan sumbu vertikal merupakan nilai temperatur dalam ${ }^{\circ} \mathrm{C}$. 


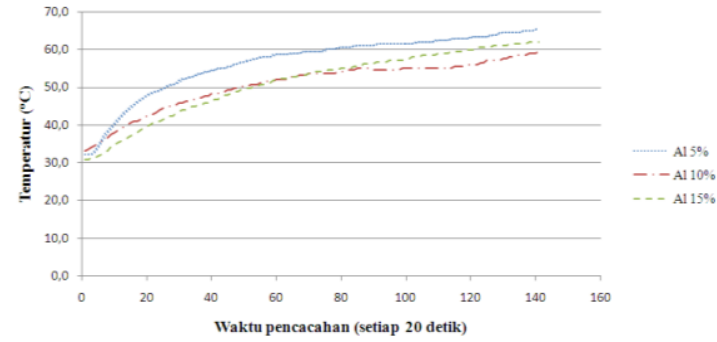

Gambar 3. Grafik temperatur permukaan atas adsorbent bed dalam fungsi waktu

Gambar 3 terdiri dari 3 buah grafik yang masing-masing mewakili tipe adsorbent bed dengan komposisi volume partikel aluminium-karbon aktif $5 \%, 10 \%$, dan $15 \%$. Grafik tersebut memiliki profil yang sama, pada rentang temperatur terukur 30-70 ${ }^{\circ} \mathrm{C}$, yang memperlihatkan kenaikan temperatur permukaan adsorbent bed seiring dengan durasi pemanasan. Temperatur permukaan adsorbed bed $5 \%$ lebih tinggi dari tipe lainnya. Hal ini diduga karena adsorbent bed dengan kandungan partikel aluminium 5\% memiliki konduktivitas termal rendah sehingga panas yang diterima oleh permukaan adsorbent bed tidak banyak diteruskan melintas bed. Panas tersebut terakumulasi yang menyebabkan kenaikan temperatur pada permukaan bed.

Pada adsorbent bed $10 \%$ dan $15 \%$ terjadi kondisi trade-off yaitu pada kisaran temperatur 55 ${ }^{\circ} \mathrm{C}$. Pada rentang temperatur $30-55{ }^{\circ} \mathrm{C}$, temperatur adsorbent bed $10 \%$ lebih tinggi daripada bed $15 \%$. Namun, pada rentang 55-70 ${ }^{\circ} \mathrm{C}$ temperatur adsorbent bed $15 \%$ lebih tinggi daripada bed $10 \%$. Kondisi ini perlu diinvestigasi lebih lanjut. Dugaan sementara adalah bahwa pada kondisi tersebut terjadi perubahan gradien temperatur sehingga panas yang diterima oleh bed $15 \%$ berubah yang mengakibatkan temperatur permukaan meningkat. Perubahan gradien temperatur ini diduga adanya perbedaan koefisien konveksi di sekitas bed pada saat pengambilan data yang terpisah.

Konduktivitas adsorbent bed untuk komposisi volume aluminium-karbon aktif 5\%, 10\%, dan $15 \%$

Konduktivitas termal adsorbent bed merupakan konduktivitas termal material komposit yang terdiri dari aluminium dan karbon aktif dengan nilai konduktivitas termal aluminium 237 $\mathrm{Wm}^{-1} \mathrm{~K}^{-1}$ dan nilai konduktivitas termal karbon 1,6 $\mathrm{Wm}^{-1} \mathrm{~K}^{-1}$. Konduktivitas termal pada rentang temperatur permukaan $30-70{ }^{\circ} \mathrm{C}$ dari ketiga tipe adsorbent bed dapat dilihat pada Gambar 4. Gambar tersebut memperlihatkan bahwa pada rentang temperatur permukaan $30-70{ }^{\circ} \mathrm{C}$ nilai konduktivitas termal adsorbent bed relatif konstan.

Adsorbent bed dengan penambahan aluminium $15 \%$ mempunyai nilai konduktivitas termal tertinggi yaitu sekitar $32,5 \mathrm{Wm}^{-1} \mathrm{~K}^{-1}$. Nilai konduktivitas termal adsorbent bed $10 \%$ dan $5 \%$ berturut-turut adalah $23,5 \mathrm{Wm}^{-1} \mathrm{~K}^{-1}$ dan $12,5 \mathrm{Wm}^{-}$ ${ }^{1} \mathrm{~K}^{-1}$. Peningkatan nilai konduktivitas termal Adsorbent bed dengan penambahan volume partikel aluminium $5 \%, 10 \%$, dan $15 \%$ yang dibandingkan dengan adsorbent bed karbon aktif adalah $10,9 \mathrm{Wm}^{-}$ ${ }^{1} \mathrm{~K}^{-1} ; 21,9 \mathrm{Wm}^{-1} \mathrm{~K}^{-1}$; dan $30,9 \mathrm{Wm}^{-1} \mathrm{~K}^{-1}$.

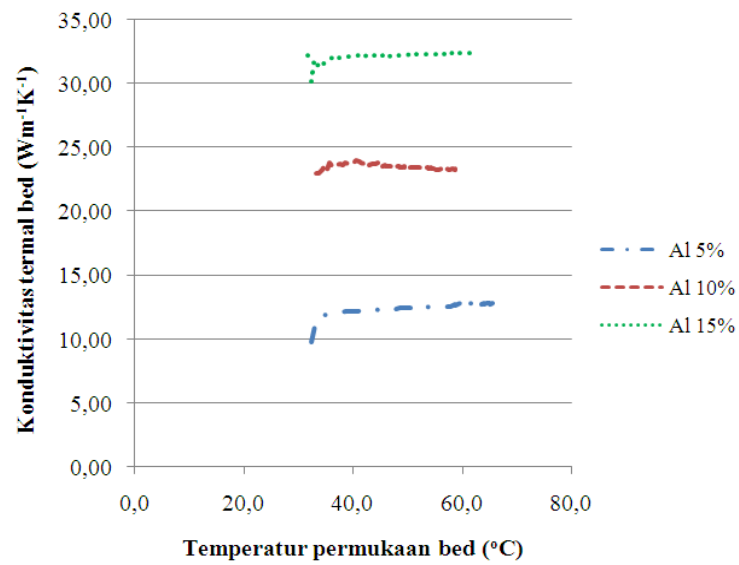

Gambar 4. Konduktivitas termal adsorbent bed $\left(\mathrm{Wm}^{-1} \mathrm{~K}^{-1}\right)$

Gambar 5 merupakan perbandingan antara nilai konduktivitas termal pada temperatur permukaan yang sama untuk hasil eksperimen dan nilai konduktivitas termal kalkulasi. Apabila ditarik garis dengan gradien 1 maka tampak bahwa nilai konduktivitas termal hasil eksperimen lebih tinggi daripada nilai konduktivitas termal kalkulasi. Persentase perbedaan tersebut menurun seiring dengan meningkatnya temperatur permukaan bed, seperti terlihat pada Gambar 6. Persentase perbedaan yang relatif tinggi berkisar pada nilai $45 \%$, sedangkan perbedaan yang relatif rendah berkisar pada $10 \%$. Rentang perbedaan yang rendah yaitu $10-20 \%$ terjadi pada rentang temperatur 55-65 ${ }^{\mathrm{O}} \mathrm{C}$.

Rentang persentase perbedaan nilai konduktivitas termal eksperimen dan kalkulasi sebesar 58\% ini lebih tinggi dibandingkan dengan yang dilakukan oleh Demir et al. yaitu $30 \%$. Namun, rentang nilai persentase dari Demir et al adalah untuk adsorbent bed de ngan material silica gel dan aluminium.

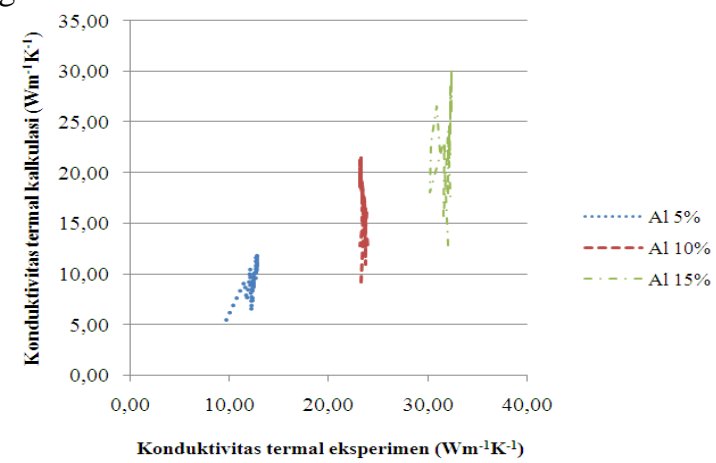

Gambar 5. Perbandingan antara konduktivitas termal adsorbent bed eksperimen dengan konduktivitas termal adsorbent bed kalkulasi 


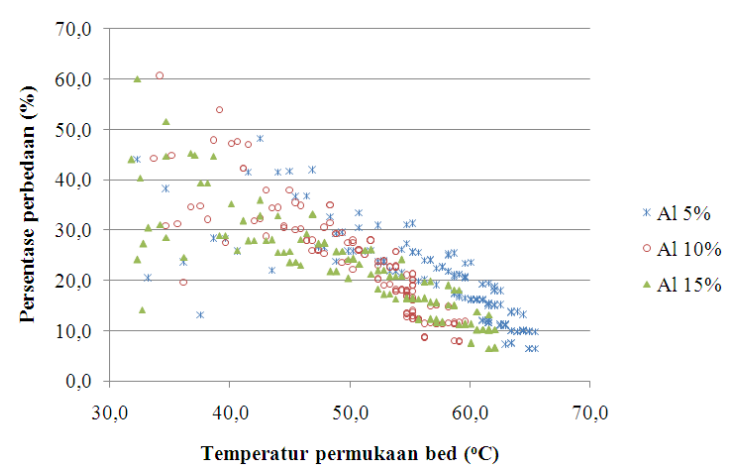

Gambar 6. Persentase perbedaan nilai konduktivitas termal adsorbent bed eksperimen dengan konduktivitas termal adsorbent bed kalkulasi

\section{KESIMPULAN}

Hasil penelitian menunjukkan adanya perbedaan konduktivitas termal pada setiap adsorbent bed yang diteliti yang dirangkum sebagai berikut:

- Penambahan volume partikel aluminium 5\%, $10 \%$, dan $15 \%$ kedalam adsorbent bed berdampak pada peningkatan konduktivitas termal bed sebesar $10,9 \mathrm{Wm}^{-1} \mathrm{~K}^{-1} ; 21,9 \mathrm{Wm}^{-}$ ${ }^{1} \mathrm{~K}^{-1}$; dan $30,9 \mathrm{Wm}^{-1} \mathrm{~K}^{-1}$.

- $\quad$ Peningkatan konduktivitas termal berdampak pada gradien temperatur yang secara keseluruhan dapat meningkatkan temparatur bed.

\section{UCAPAN TERIMA KASIH}

Pada kesempatan ini Tim Peneliti mengucapkan terima kasih banyak kepada Fakultas Teknik Undip dan Universitas Diponegoro Semarang yang telah memberikan fasilitas pendanaan penelitian pemula ini.

\section{DAFTAR PUSTAKA}

1. Critoph R.E., 1994. An ammonia carbon solar refrigeration for vaccine cooling, Renewable Energy 5 (Part I) 502-508

2. Demir, H., M. Mobedi, and S. Ülkü, The use of metal piece additives to enhance heat transfer rate through an unconsolidated adsorbent bed. International Journal of Refrigeration, 2010. 33(4): p. 714-720.

3. Eun, T.-H., et al., Enhancement of heat and mass transfer in silica-expanded graphite composite blocks for adsorption heat pumps. Part II. Cooling system using the composite blocks. International Journal of Refrigeration, 2000. 23(1): p. 74-81.

4. Freni, A., et al., Zeolite synthesised on copper foam for adsorption chillers: A mathematical model. Microporous and Mesoporous Materials, 2009. 120(3): p. 402409.

5. Hamilton, R.1. and O.K. Crosser, Thermal conductivity of hetrogeneous twocomponent systems. Industrial and
Engineering Chemistry Fundamentals, 1962. 1: p. 187-191.

6. Hu, P., J.-J. Yao, and Z.-S. Chen, Analysis for composite zeolite/foam aluminum-water mass recovery adsorption refrigeration system driven by engine exhaust heat. Energy Conversion and Management, 2009. 50(2): p. 255-261.

7. Khattab N.M., 2004. A novel solar-powered adsorption refrigeration module, Applied Thermal Engineering 24, 2747-2760

8. Lemmini F., J. Buret-Bahraoui, 1990. Performance of an adsorptive solar refrigerator using two types of activated carbon, Energy and Environment 2 774-779, World Renewable Energy Congress.

9. Meunier F, Douss N., 1990. Performance of adsorption heat pumps: active-carbonmethanol and zeolite-water pairs. In: Trans. ASHRAE Meeting, Saint Louis, USA.. p. 4918.

10. Meunier F., 1994. Sorption solar cooling, Renewable Energy 5 (Part I) 422-429.

11. Pons M., J.J. Guilleminot, 1986. Design of an experimental solarpowered, solidadsorption ice maker, Transactions of the ASME, Journal of Solar Energy Engineering 108 (November) 332-337.

12. Pons M., 1987. Experimental date on a solar-powered ice maker using activated carbon and methanol adsorption pair. Trans ASME, J Sol Energy Eng 1987;109(4):30310.

13. Pridasawas W., 2006. Solar-Driven Refrigeration Systems with Focus on the Ejector Cycle, Doctoral Thesis, Royal Institute of Technology, KTH, Denmark.

14. Restuccia, G., A. Freni, and G. Maggio, A zeolite-coated bed for air conditioning adsorption systems: parametric study of heat and mass transfer by dynamic simulation. Applied Thermal Engineering, 2002. 22(6): p. 619-630.

15. Sumathy K., K.H. Yeung, Li Yong., 2003. Technology development in the solar adsorption refrigeration systems, Progress in Energy and Combustion Science 29 301327.

16. Wang RZ., 2001. Performance improvement of adsorption cooling by heat and mass recovery operation. Int $\mathrm{J}$ Refrigeration 2001;24:602-11.

17. Wang, S.G., R.Z. Wang, and X.R. Li, Research and development of consolidated adsorbent for adsorption systems. Renewable Energy, 2005. 30(9): p. 14251441.

18. Wang L.W., R.Z. Wang, Z.S.Lu, C.J. Chen, K. Wang , Wang, J.Y Wu., 2006. The performance of two adsorption ice making 
test units using activated carbon and a carbon composite as adsorbent, Carbon 44 2671-2680.

19. Yeung K.H. and Sumathy K., 2003. Thermodynamic analysis and optimization of a combined adsorption heating and cooling system, INTERNATIONAL JOURNAL OF ENERGY RESEARCH Int. J. Energy Res.; 27:1299-1315 (DOI: 10.1002/er.944) 